\title{
ТРАНСФОРМАЦИЯ БИЗНЕС-МОДЕЛИ БАНКА В УСЛОВИЯХ ЦИФРОВОЙ ЭКОНОМИКИ
}

\author{
Ю.Б. Бубнова \\ Байкальский государственный университет, г. Иркутск, Российская Федерация
}

\section{Информация о статье}

Дата поступления

16 июля 2019 г.

Дата принятия к печати 30 августа 2019 г.

Дата онлайн-размещения 12 сентября 2019 г.

\section{Ключевые слова}

Цифровая экономика; банк; диджитализация; финансовые технологии; бизнес-модель

\begin{abstract}
Аннотация
Информационные технологии, искусственный интеллект проникают в банковскую сферу, делая ее более мобильной и гибкой. Меняются потребности и предпочтения клиентов, способы предоставления финансовых услуг. На рынке финансовых услуг значительную роль начинают играть IT-компании, предлагающие традиционные банковские продукты в новом, современном формате. Банкам приходится инвестировать огромные средства в развитие банковских инноваций, чтобы оставаться востребованными. Все это требует от них не только изменения способов оказания своих услуг и коммуникации с клиентами, но и качественной перестройки операционных процессов, методов и подходов к управлению ими, корпоративной культуры. В статье рассмотрено изменение основных составляющих системы управления банком под влиянием внедряемых цифровых технологий: клиентского сегмента, операционных процессов и бизнес-модели. Особое внимание уделено необходимости изменения существующей бизнес-модели банка. Обобщены основные финансовые технологии, позволяющие трансформировать банковскую деятельность в соответствии с требованиями цифровой экономики.
\end{abstract}

\section{TRANSFORMATION OF BANK'S BUSINESS MODEL IN TERMS OF DIGITAL ECONOMY}

\author{
Yulia B. Bubnova \\ Baikal State University, Irkutsk, the Russian Federation
}

\section{Article info}

Received

July 16, 2019

Accepted

August 30, 2019

Available online

September 12, 2019

\section{Keywords}

Digital economy; Bank;

digitalization; financial

technologies; business model

\begin{abstract}
Information technology, artificial intelligence penetrate into the banking sector, making it more mobile and flexible. Needs and preferences of customers, ways of providing financial services are changing. IT-companies that offer traditional banking products in a new, present day's format are entering the financial services market. Banks have to invest huge amounts of money in developing banking innovations in order to remain in demand. All this requires banks to change not only the ways of providing their services and communication with customers, but also the qualitative restructuring of operational processes, methods and approaches to their management, corporate culture. The article examines the changes in the main components of the banking management system under the influence of digital technologies: the customer segment, the operating processes and the business model. It pays particular attention to the need of changing the existing banking business mode. It summarizes the main financial technologies that allow to transform banking business in accordance with the requirements of the digital economy.
\end{abstract}

Финансовые технологии (финтех) оказырование современной банковской системы. Многие аналитические агентства и консалтинговые компании публикуют прогнозы, предвещающие исчезновение традиционных банковских структур уже через пять - десять лет. Ежегодно десятки миллиардов долларов инвестируется в финтех-индустрию. Все большую роль в данной отрасли начинают играть технологические компании, такие как Google, Microsoft, Intel, которые до этого не предо- 
ставляли банковские продукты и услуги. Эти IT-гиганты делают существенные инвестиции в финтех, что провоцирует появление в последнее время большого количества финансовых стартапов, успешно реализуемых. Новые структуры достаточно гибки и мобильны и не входят в сореру банковского регулирования и контроля, что позволяет им предлагать на рынке новые кредитные, инвестиционные и платежные услуги. Все это создает серьезную конкуренцию традиционным банковским структурам и требует от них немедленной реакции. Трансформация банковского бизнеса, осуществление операций в соответствии с требованиями цифровой экономики являются весьма актуальными задачами.

Финансовые технологии широко используются для осуществления платежей, кредитования, инвестирования и т.д. Данные аспекты широко освещались в работах как российских, так и зарубежных авторов [1-5]. Немало работ посвящено результатам внедрения технологий обработки больших данных [6-8], созданию банками новых виртуальных каналов продвижения своих продуктов [4; 7 ; 9]. Рядом авторов [10-12] рассматриваются отдельные аспекты трансформации банковского бизнеса и системы управления им. Несмотря на всю широту обсуждения необходимости внедрения в банковскую сферу финансовых технологий и ее цифровизацию, особенностей и преимуществ данных технологий, вопросы кардинальной перестройки банковского бизнеса, смены бизнес-модели банка рассмотрены недостаточно полно, что и определяет научную новизну исследования.

Целью данного исследования является определение основных направлений трансформации банковской деятельности в условиях цифровой экономики, выявление дальнейших тенденций ее развития. В этой связи автором данной статьи поставлены задачи: рассмотреть основные изменения в подходах к управлению клиентами, операционными процессами банка под воздействием внедряемых цифровых технологий, представить основные направления, по которым будет происходить смена бизнес-модели банка.

Сегодня созданы все необходимые предпосылки для обеспечения перехода банковской системы от экстенсивной модели развития к интенсивной. Развитие информационных технологий влечет трансформацию банковских бизнес-процессов, что предполагает изменения в управлении банком. Цифровая экономика проникает во все сореры управления, что предполагает интеграцию внедренных ранее разрозненных технологий, а следова- тельно, абсолютно новые подходы к управлению операционными и бизнес-процессами.

Принципы цифровой экономики не могут работать на основе существующей управленческой и операционной модели, поэтому требуется перестройка не только внешних, но и внутренних структурных звеньев и связей между ними. Действующая модель построения банковского бизнеса, операционной деятельности и системы управления долгое время ориентировалась на постепенное развитие и внедрение новых технологий и не предполагала масштабной трансформации и перехода в цифровую сферу. Крупнейшие игроки российского банковского рынка, которые масштабно внедряют финансовые технологии и IT-системы, виртуальные каналы коммуникаций, сталкиваются с необходимостью изменения мышления своих сотрудников, причем на всех уровнях иерархии (от руководителей до персонала операционного отдела), внедрения новой культуры ведения банковского бизнеса.

В современном банковском бизнесе руководители банков сосредоточены на трех ключевых направлениях деятельности: клиенты, операционные процессы и бизнес-модели. Именно в этих трех направлениях идет трансорормация.

Клиенты банка становятся не просто потребителями услуг, а их генератором. На основе доступных технологий банки собирают большой объем данных о клиенте, его запросах и способны сорормировать и предложить ему необходимую услугу или их комплекс, при этом предоставлены они будут в удобном для клиента формате. Изменения в клиентской структуре также оказывают влияние на применяемые банком технологии. Внедрение систем, позволяющих собрать максимальный объем сведений о клиенте и, как следствие, дающих возможность сфрормировать «картину современного потребителя» и на ее базе предложить актуальную услугу, является конкурентным преимуществом. Как правило, кто быстрее и качественнее отреагировал на рыночный спрос, тот одержал победу в борьбе за клиента. Именно поэтому просто разработать и применить в своей деятельности новую технологию уже недостаточно, современный экономический рынок требует «предугадать» и определить тренды заранее, нужен более комплексный подход. В этом плане на помощь банкам приходят технологии цифровой демографии.

На сегодняшний момент основными потребителями банковских услуг становятся представители поколения Y (миллениалы) и Z 
(центениалы), для которых смартфон выступает самым главным персонализированным техническим устройством. Распространение мобильных устройств предполагает их использование для предоставления большого количества продуктов и услуг в режиме реального времени через удаленные каналы связи. Мгновенное реагирование на поступающие клиентские запросы станет ключевой компетенцией и преимуществом банка. Поэтому мобильные приложения, а также сервисы самообслуживания становятся основным способом предоставления банковских услуг. Здесь банкам необходимо учитывать предпочтения клиентов. Все более приветствуется персонализация банковских предложений, при этом максимальное предпочтение отдается цифровым каналам передачи данных.

Трансформация в данном направлении ориентирована на повышение качества обслуживания клиентов: обеспечение доступа к услугам в режиме 24/7, персонализация и пакетирование услуг на основе финансовых технологий. Это обеспечит банку лояльность клиентов, стабилизирует его клиентскую базу, позволит ему расширить спектр предоставляемых услуг и, как итог, приведет к снижению операционных издержек, росту доходов.

Трансорормация операционных процессов связана с таким термином, как digital-трансформация, или диджитализация. Лучшие компании, так называемая цифроэлита (Digirati), сочетают активность в сфере цифровых технологий и сильное руководство, совершая переход от просто использования IT к масштабному изменению бизнеса [13].
В процессе так называемой диджитализации происходит изменение операционной деятельности банков путем их переориентации на новые ценности и потребности клиентов, повышение эфффективности банковских услуг за счет их комплексности и сокращение операционных издержек, связанных с содержанием офисов (заработная плата сотрудников, аренда и содержание имущества). Экстенсивность развития предполагает внедрение все новых (экономичных) инноваций. Таким образом, банковский бизнес трансорормируется и становится более эфрфективным (достигается операционная эфрфективность).

Этому уже сейчас есть подтверждение. Самые большие вложения в финтех осуществляют самые крупные многофилиальные банки, и именно у них наблюдается повышение рентабельности деятельности за счет сокращения операционных расходов при росте инвестиций в инновации. Для разработки и внедрения передовых технологий, отвечающих требованиям цифровой экономики, российские банки вынуждены создавать собственные дочерние предприятия либо обращаться в действующие IT-компании. Выручка крупнейших IT-компаний от банковских проектов представлена в таблице.

В 2018 г. рейтинговыми агентствами «Эксперт РА» и RAEX («РАЭКС-Аналитика») было проведено исследование. В его ходе крупнейшие российские банки отметили направления банковской деятельности, на которые внедрение искусственного интеллекта может повлиять с максимальной выгодой для банка (рис. 1).

Выручка крупнейших российских IT-компаний от проектов в банках *

\begin{tabular}{|c|c|c|c|c|}
\hline Компания & $\begin{array}{l}2017 \\
\text { млн р. }\end{array}$ & $\begin{array}{l}2016, \\
\text { млн р. }\end{array}$ & $\begin{array}{l}\text { Динамика } \\
2017 / 2016\end{array}$ & Ключевые клиенты \\
\hline $\begin{array}{l}\text { «Сбербанк-Техно- } \\
\text { логии» }\end{array}$ & 30320,0 & 20341,0 & 49,1 & ПАО «Сбербанк» \\
\hline ГК «Техносерв» & 13822,1 & 13386,1 & 3,3 & $\begin{array}{l}\text { ПАО «Сбербанк», Банк России, ВТБ, ПАО } \\
\text { «ромсвязьбанк», банк «ФК Открытие» }\end{array}$ \\
\hline Холдинг ITG & 12618,0 & 12040,0 & 4,8 & $\begin{array}{l}\text { ПАО «Сбербанк», АО «Газпромбанк», АО } \\
\text { «Райффрайзенбанк», ВТБ, ПАО «Росгос- } \\
\text { страх Банк», АО «Альфра-Банк», АО «Банк } \\
\text { Русский Стандарт», Московский кредитный } \\
\text { банк, ПАО АКБ «Связь-Банк» }\end{array}$ \\
\hline $\begin{array}{l}\text { «нфоосистемы } \\
\text { Джет» }\end{array}$ & 10128,3 & 8847,6 & 14,5 & $\begin{array}{l}\text { НСПК, ПАО АКБ «Связь-Банк», ПАО } \\
\text { «Банк УРАЛСИБ», ПАО «Сбербанк», ВТБ, } \\
\text { АО «Газпромбанк», АО «Банк Русский } \\
\text { Стандарт», ПАО «Росбанк» и др. }\end{array}$ \\
\hline
\end{tabular}

* Составлена по данным: Обзор: ИТ в банках 2018. URL: http://www.tadviser.ru/index.php/Статья:Обзор:_ ИТ_в_банках_2018. 


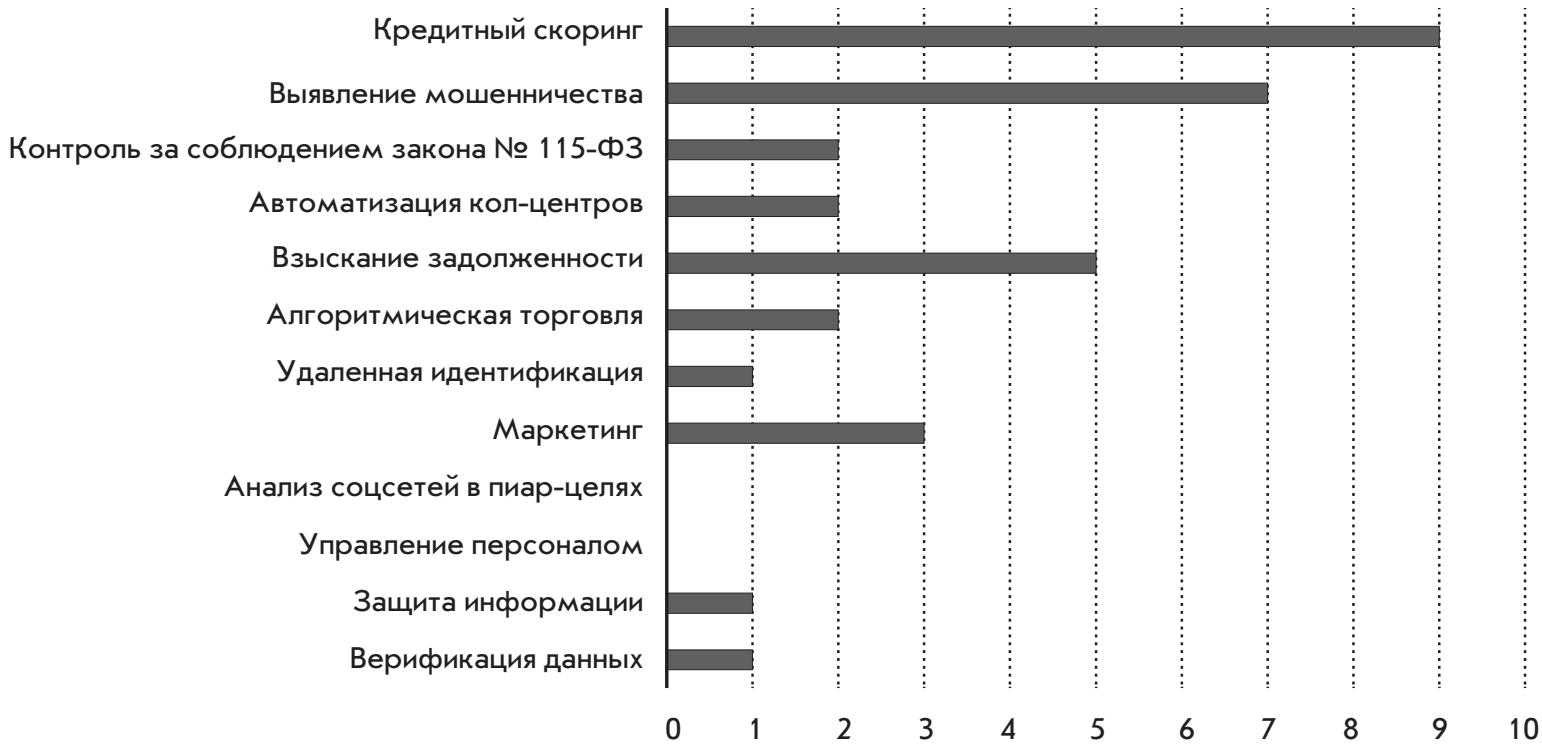

Рис. 1. Области применения искусственного интеллекта в банковской практике с наибольшим потенциалом

Источник: Искусственный интеллект в банковском секторе. URL: https://raex-a.ru/researches/bank/ bank_ai_2018/part3

Наибольшие вложения 70 \% банков до 2021 г. предполагаются в сфрерах облачных технологий, мобильного банкинга и обработки информации. Порядка 50 \% кредитных организаций выделяют развитие систем биометрии, повышение уровня кибербезопасности и внедрение искусственного интеллекта как первостепенные задачи.

По данным McKinsey за 2018 г., уже порядка 76 \% коммерческих банков США в своей деятельности применяют Big Data, a 34 \% вложились в развитие данной технологии. Внедрение Big Dała, согласно исследованию, сможет повысить уровень доверия к банкам, расширить их клиентскую базу и улучшить их коммуникацию с потребителями банковских услуг. Помимо этого, анализ Big Data снижает уровень рискованности операций, помогает в борьбе с мошенничеством, стимулирует создание системы риск-менеджмента и способствует автоматизации внутренних бизнес-процессов. Примером повышения уровня кибербезопасности благодаря применению технологии Big Data выступает система антифрода Visa, которая в онлайн-режиме определяет незаконные действия по ряду специфических признаков и, как следствие, предотвращает мошенничества на 2 млрд дол. ежегодно.

Совсем недавно велись разговоры о необходимости создания для банков интернет-платформ и виртуальных маркетплейсов с целью реализации и продвижения ими своих продуктов и услуг, а также товаров и услуг нефинансовых компаний, являющихся афффилированными банковскими компаниями или партнерами кредитных организаций. Примеры реализации таких платформ уже есть. Почти два года действуют платформы «ДомКлик» и «Беру» от Сбербанка, сервис Tinkoff.travel от «Тинькофрф Банка». Даже Банк России совместно с Московской биржей, ее Национальным расчетным депозитарием, пятью банками и несколькими информационными порталами в текущем периоде апробирует маркетплейс финансовых услуг. Данный тренд отражает, что будущее фринансового сектора заключается прежде всего в предложении не только стандартных банковских услуг, но и дополнительных персонализированных сервисов. Успешность существующих платформ говорит о том, что подобных примеров со временем станет больше.

Уже идет процесс превращения банков в сервисные компании, в которых финансовые услуги являются основными, но не единственными. Многие банки активно предлагают своим и чужим клиентам юридические, бухгалтерские, налоговые, страховые, документарные, туристические, телекоммуникационные, брокерские, государственные услуги и т.п. Для банков это источник дополнительных комиссий и клиентов. Особенно продвинулись в данном направлении АО «Тинькофрф Банк» и ПАО «Сбербанк». Такая деятельность требует обширной автоматизации взаимодействия с поставщиками 
услуг. Его полномасштабная фринансовая и техническая реализация под силу только крупным банкам - именно они становятся универсальными провайдерами услуг В2С и В2В с упором на финансовую составляющую, а небольшие банки остаются банками в классическом понимании этого слова.

Основным полем внедрения методов цифровой экономики в банковском секторе является применение интеллектуализированных вычислений, технологий больших данных на основе интеграции роботизации и машинного самообучения, другими словами - менеджмент, основанный на данных и знаниях, или, иначе, Data Driven \& Data Science. Kлассическим примером являются ВРМ-системы (business process management) - управление деловыми процессами, которое предполагает использование средств автоматизации (к примеру, СУБД) и интеграцию информационных технологий, необходимых в процессе принятия управленческих решений [8].

Bce это требует увеличения IT-потенциала банковского сектора, а также нестандартного подхода к управлению финансовыми учреждениями в целом.

По результатам исследования Banking Technology Vision 2019, проведенного консалтинговой компанией Accenture, топ-менеджеры и IT-руководители 748 банков из 30 стран мира признали, что с 2015 г. скорость технологической трансформации в их организациях существенно выросла. 73 \% респондентов отметили, что таким изменениям поспособствовало развитие SMAC-технологий (социальные, мобильные, аналитические и облачные технологии).

Чем выше статус руководителя, тем меньше времени он готов тратить на анализ данных и тем бо́льшую ответственности за принятие решений он несет. Поэтому с ростом статуса потребителя аналитики в банке меняются его требования к ІТ-инструментам. Так, аналитикам необходимы более мобильные и гибкие средства, позволяющие всесторонне изучать различные факторы, выявлять скрытые закономерности, менеджерам среднего звена нужны инструменты, дающие возможность быстро и полно проанализировать ситуацию на локальном рынке для оперативного принятия решений, для руководителей высшего звена (топ-менеджеров) важен мониторинг внешних событий, оказывающих существенное влияние на банковскую деятельность, контроль уровня внутренних бизнес-показателей.

Здесь очень большую роль играет правильно выстроенная архитектура бизнеса.
Как и для всех коммерческих структур, для банка характерна трехуровневая IT-архитектура. Первый уровень - стратегический, включающий цели и задачи банка, основные функции. Второй - операционный (процессный) уровень, предполагающий фрормирование модели данных и архитектуры информационных систем. Третий уровень представляет собой инфраструктуру программного обеспечения, аппаратных средств и приложений. Именно последний уровень в настоящее время претерпевает существенную трансформацию.

Аутсорсинг прочно вошел в банковскую деятельность. Помимо охранных и инкассаторских услуг, банки готовы передавать на аутсорсинг свои внутренние процессы. Все больше кредитных организаций осознает, что значительное количество бэк-офисов не является конкурентным преимуществом. Для оптимизации расходов на их содержание бэк-офисы необходимо централизовать. Единый бэк-офисный центр можно создавать для нескольких банков по примеру уже созданных общих процессинговых центров по платежным сервисам. На сегодняшний момент уже есть поставщики, готовые предложить такие центры в облаке. У банков будет возможность выбирать, какие компании смогут предоставить им более полный спектр услуг по ведению бухгалтерии, риск-менеджменту, процессингу. Каналы взаимодействия с клиентами и партнерами банки также смогут приобретать извне.

Всестороннее использование Интернета и социальных сетей для корпоративных нужд изменило требования к банковским сетям передачи данных и их центрам обработки данных. Переход с физической инфраструктуры на виртуальную требует увеличения производительности сетевой инфраструктуры: гибкость, мобильность, контроль. Гибкость инфраструктуры подразумевает ее быструю перенастройку под меняющиеся требования бизнеса, моментальное реагирование в предоставлении ресурсов и сервисов. Мобильность - поддержка механизмов миграции, независимость от фризического транспорта и IP-адресации, быстрота аккумуляции и перераспределения ресурсов. Контроль предполагает видимость и контроль трафика как в физической инфраструктуре, так и в виртуальной.

Переход к безналичному обществу и повышение зависимости от дистанционных каналов связи (посредством сети Интернет) обусловливают трансформацию системы управления капиталом. Система банков- 
ского обслуживания также претерпевает изменения, наибольшее внимание уделяется децентрализованным криптографическим системам. Система распределенного реестра и открытый исходный код способствуют снижению затрат на внедрение банковских технологий и при этом повышают устойчивость банка. Центральный банк сможет вводить интернет-стандарты, которые будут выполнять функции технологически настроенных регуляторов. Это обеспечит доступ к услугам всем субъектам, соответствующим стандартам, обеспечив при этом криптографическое подтверждение личности клиента и его платежеспособности. Компании смогут работать с большей прозрачностью операций и сделок, а потребители - покупать товары и пользоваться услугами с большей конфиденциальностью.

Цифровизация банковского бизнеса предполагает изменения в применяемой бизнес-модели. Наряду с вертикальной используют горизонтальную модель построения банковского бизнеса. Смена модели банковского бизнеса влечет изменения в управлении персоналом банка. Сегодня для банков более востребованными становятся специалисты, обладающие современными компетенциями в технологическом направлении. Например, на рынке труда повышается спрос на специалистов на должность Data Scientist - это универсальный экономист с навыками программиста, который занимается интеллектуальной обработкой данных.

В штат принимают новых сотрудников, например Chief Digital Officer (CDO) - менеджера по цифровой трансформации. Также организации вырабатывают гибкие подходы к разработке программного обеспечения Agile, принимают к сотрудничеству финтех-стартапы, обеспечивают доступ к IT-платформам собственной разработки.

Большим спросом пользуется и должность аналитика больших данных - специалиста, который обладает математическими, статистическими, экономическими, управленческими знаниями, знаниями в области информатики и компьютерных наук. Основное направление деятельности аналитика больших данных - работа с Big Dała. B его обязанности входит обработка большого массива неструктурированной информации и формирование на основе полученных результатов обоснованных выводов по изучаемой теме. Деятельность аналитика больших данных позволяет банкам совершать технологические прорывы, открывать новые перспективы, повышать эфффективность сво- ей деятельности, расширять возможности в части дохода, рынка сбыта, новых продуктов и т.д. Главная компетенция такого сотрудника - способность обнаруживать логические связи в массиве полученной информации и на основании этого разрабатывать совершенно новые модели банковской деятельности.

Специалисты Data Scientist и аналитики больших данных обязаны уметь получать требуемую информацию, в том числе информационные потоки, в режиме «здесь и сейчас» из различных ресурсов и с высокой скоростью обрабатывать ее для дальнейшего принятия бизнес-решений.

Говоря о действующих сотрудниках банка, необходимо отметить, что они должны быть способны мыслить системно, быть инновационными, клиентоориентированными, склонными к саморазвитию.

Для формирования перечисленных выше компетенций банкам необходимо полностью менять систему обучения и мотивации персонала, а также модернизировать сложившиеся HR-процессы. Организация мастер-классов, приглашение различных спикеров и бизнес-тренеров, выделение бюджета на образование вне рабочего времени, «прокачка» навыков, проведение вебинаров - все это способствует формированию высококвалифицированной команды, отвечающей всем современным требованиям. Успешно развивается в этом направлении Сбербанк. В 2018 г. на базе облачного решения SAP Success Factors он реализовал свой новый проект по цифровому образованию для сотрудников банка. Облачная платформа представляет собой единый внутренний рынок труда. Сотрудники получили возможность заниматься собственным развитием с применением инструментов оценки, карьерного планирования и онлайн-обучения, видеть вакансии, а руководители - получать полную информацию о своей команде, отслеживать динамику работы каждого сотрудника, оценивать его навыки и компетенции, планировать необходимые для банка компетенции. Проект был реализован в рамках Стратегии развития Сбербанка на 2018-2020 годы с целью формирования качественно новой системы управления персоналом. Для достижения поставленной цели Сбербанк обозначил необходимым выполнение ряда задач: повышение качества подбора сотрудников, формирование благоприятной для адаптации новых работников среды, обеспечение возможности карьерного роста, прозрачное планирование, развитие современных ком- 
петенций и формирование корпоративной культуры. Помимо этого, такая система поспособствует сокращению временны́х издержек, облегчит процессы подбора, оформления и адаптации новых сотрудников и, кроме того, сорормирует сквозную модель для всей структуры банка.

Говоря о внутрибанковской структуре, необходимо отметить, что ставшая классической иерархическая модель построения персонала становится менее востребованной. На смену ей приходит командная работа, базирующаяся на принципах сотрудничества, помощи в решении возникающих трудностей и конфликтов, доверительных отношениях и возможности получения совета от начальства.

Традиционная модель банковского бизнеса изменяется под воздействием тенденций цифровизации и начинает принимать форму, представленную на рис. 2.

Таким образом, исходя из сказанного, можно определить основные направления трансформации банковского бизнеса в бли- жайшем будущем. В части управления клиентским сегментом основной тренд будет взят на использование цифровой демографии, что обеспечит персонализацию банковских услуг. Благодаря персонализированным предложениям у банка появляется возможность выстроить отношения с клиентом на качественно новом уровне: услуги в формате $24 / 7$, индивидуальный сервис, повышающий уровень доверия клиентов.

Bce это потребует качественной перестройки операционных процессов и смены бизнес-модели управления банком. Широкое внедрение и распространение в банковской практике технологий распределенных реестров (DLT), искусственного интеллекта (artificial intelligence), расширенной реальности (extended reality), квантовых вычислений (quantum) выведут банковский бизнес на качественно новый уровень организации бизнес-процессов. Использование новых технологий потребует устойчивой и безопасной взаимосвязи между программными системами банков и информационными системами

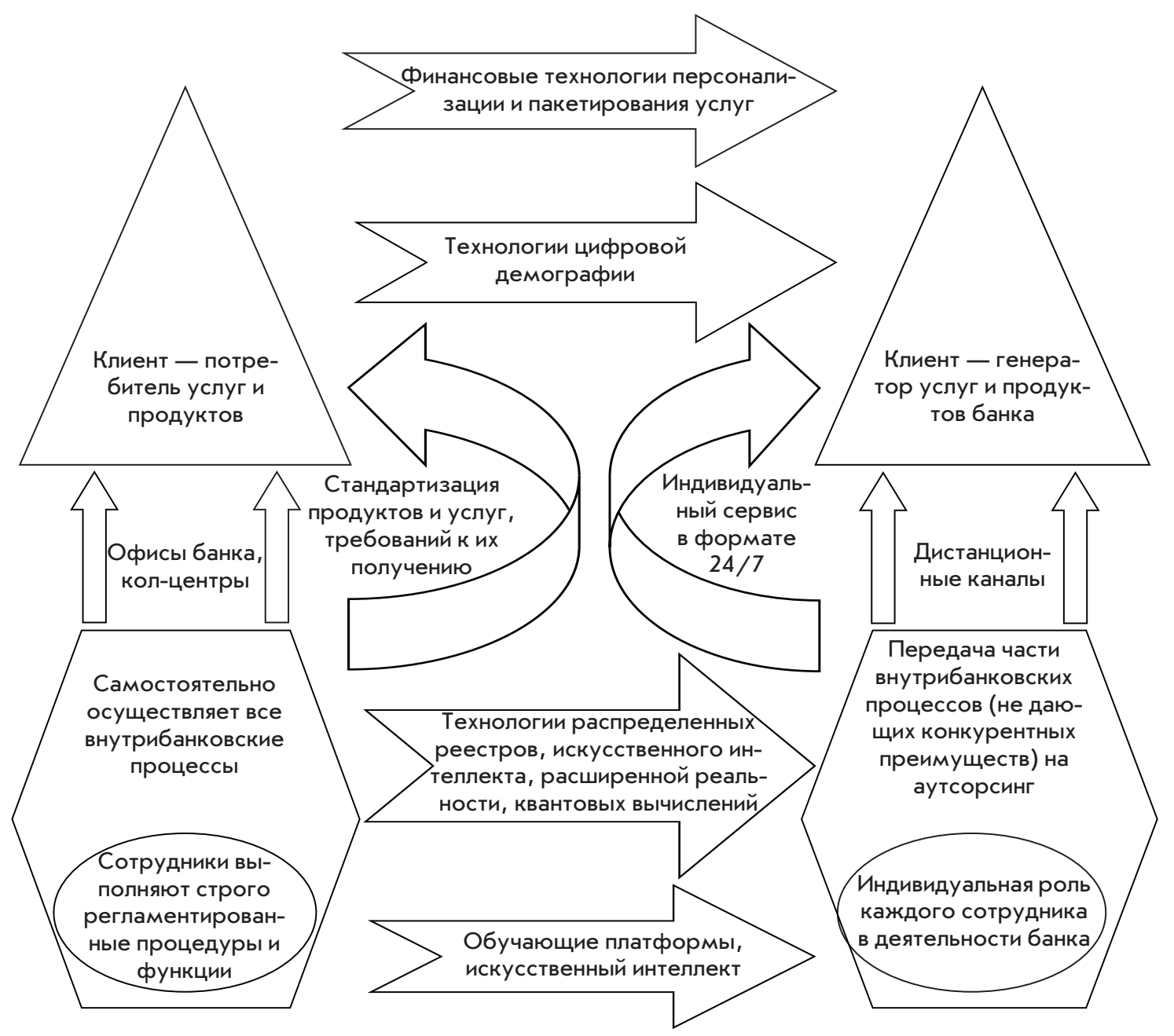

Рис. 2. Трансформация бизнес-модели банка под воздействием цифровых технологий 
партнеров и контрагентов. Для снижения рисков банкам необходимо разрабатывать системы кибербезопасности на всех уровнях.

Активное внедрение высоких технологических решений обязано сопровождаться ростом грамотности сотрудников. В банках следует использовать концепцию, предусматривающую индивидуальную роль каждого сотрудника в банковской деятельности. В перспективе предполагается выделение ключевых компетенций каждого работника и расстановка на зоны связанных технологий от искусственного интеллекта до обучающих платформ. Для обеспечения успеха при таком подходе необходимо будет создать мощную обучающую систему для персонала.

\section{СПИСОК ИСПОЛЬЗОВАННОЙ ЛИТЕРАТУРЫ}

1. Абдуллина Р.P. Информационные технологии в банковской сфере / Р.P. Абдуллина / / Novainfo.ru. 2016. - T. 1, № 47. - C. 234-237. - URL: https://novainfo.ru/article/6500.

2. Ефимова Н. Основные подходы поддержки и развития новейших фринансовых технологий (FinTech) в зарубежных странах: опыт для России / Н. Ефимова / / Проблемы теории и практики управления. - 2018. № 5. - C. 41-46.

3. Поппер Н. Цифровое золото: невероятная история Биткойна, или Как идеалисты и бизнесмены изобретают деньги заново / Н. Поппер. - Москва : Вильямс, 2016. - 368 с.

4. Цифровые технологии в банковской сфере. Российский и мировой опыт / Р.И. Чен, А.Я. Петров, Е.И. Торбеев, П.В. Лимарев // Вестник Московского университета имени С.Ю. Витте. Сер. 1, Экономика и управление. - 2018. - № 2 (25). - С. 42-49.

5. Чишти С. Финтех: Путеводитель по новейшим финансовым технологиям / С. Чишти, Я. Барберис. - Москва : Альпина Паблишер, 2016. - 343 с.

6. Белоусов А.Л. Диджитализация банковского сектора / А.Л. Белоусов, Е.Ю. Левчук // Финансы и кредит. - 2018. - Т. 24, № 2. - С. 455-464.

7. Ермоленко О.М. Развитие банковского сектора на основе современных технологий обслуживания / О.М. Ермоленко / / Научный вестник Южного института менеджмента. - 2018. - № 2. - С. 26-30.

8. Мирошниченко М.А. Исследование процессов «цифровизации» банковского сектора в рамках экосистемы цифровой экономики России / М.А. Мирошниченко, К.-А.И. Трелевская, Е.В. Мамыкина. - DOІ: 10.21515/1990-4665-133-034 / / Научный журнал КубГАУ. - 2017. — № 133. - С. 434-447.

9. Кудрявцева А.М. Зарубежный опыт применения интернет-технологий для воздействия на целевую аудиторию коммерческого банка / А.М. Кудрявцева // Экономика и социум. - 2018. - № 1 (44). - С. 13791388.

10. Хоткин А.В. Использование IT для оптимизации деятельности современных банков / А.В. Хоткин // Теория и практика общественного развития. - 2018. - № 6. - С. 59-62.

11. Табунщиков Ю.А. Цифровизация экономики - тенденция глобального масштаба / Ю.А. Табунщиков / / Энергосбережение. - 2018. - № 7. - С. 1-13.

12. Казаренкова Н.П. Трансформация банковской системы России под влиянием цифровизации экономики / Н.П. Казаренкова, Т.А. Световцева / / Известия Юго-Западного государственного университета. Сер.: Экономика. Социология. Менеджмент. - 2018. - Т. 8, № 4 (29). - С. 188-195.

13. Вестерман Дж. Девять основ цифровой трансформации / Дж. Вестерман, Д. Боннэ, Э. Макафи. URL: http://tops.ru/blog/9_osnov_digital_transformacii.

\section{REFERENCES}

1. Abdullina R.R. Information Technologies in Banking Sector. Novainfo.ru, 2016, vol. 1, no. 47, pp. $234-237$. Available at: https: / / novainfo.ru/article/6500. (In Russian).

2. Efimova N. Main Approaches to Cutting-Edge FinTech Support and Development in Foreign Countries: Experience for Russia. Problemy teorii i praktiki upravleniya = Theoretical and Practical Aspects of Management, 2018, no. 5, pp. 41-46. (In Russian).

3. Popper N. Digital Gold: Bitcoin and the Inside Story of the Misfits and Millionaires Trying to Reinvent Money. New York, 2015. 432 p. (Russ. ed.: Popper N. Tsifrovoe zoloto: neveroyatnaya istoriya Bitkoina, ili Kak idealisty $i$ biznesmeny izobretayut den'gi zanovo. Moscow, Vil'yams Publ., 2016. 368 p.).

4. Chang R.I., Petrov A.Ya., Torbeev E.I., Limarev P.V. Digital Technologies in Banking Service. Russian and International Experience. Vestnik Moskovskogo universiteta imeni S. Yu. Vitte. Seriya 1, Ekonomika i upravlenie = Moscow Witte University Bulletin. Series 1, Economics and management, 2018, no. 2 (25), pp. 42-49. (In Russian).

5. Chishti S., Barberis J. The FINTECH Book: The Financial Technology Handbook for Investors, Entrepreneurs and Visionaries. New York, Wiley, 2016. 312 p. (Russ. ed.: Chishti S., Barberis J. Fintekh: Putevoditel' po noveishim finansovym tekhnologiyam. Moscow, Al'pina Pablisher Publ., 2016. 343 p.).

6. Belousov A.L., Levchuk E.Yu. Digitalization of the Banking Sector. Finansy $i$ kredit=Finance and credit, 2018, vol. 24, no. 2, pp. 455-464. (In Russian).

7. Ermolenko O.M. Development of the banking sector on the basis of modern technologies of service. Nauchnyi vestnik Yuzhnogo instituta menedzhmenta = Scientific bulletin of the Southern Institute of Management, 2018, no. 2, pp. 26-30. (In Russian).

8. Miroshnichenko M.A., Trelevskaya C.-A.I., Mamykina E.V. Studying the Process of «Digitalization» of the Banking Sector Within the Framework of the Ecosystem of the Digital Economy in Russia. Nauchnyi zhurnal KubGAU = Scientific Journal of KubSAU, 2017, no. 133, pp. 434-447. DOI: 10.21515/1990-4665-133-034. (In Russian). 
9. Kudryavtseva A.M. Foreign Experience of Application of Internet Technologies for Impact on the Target Audience of the Commercial Bank. Ekonomika i sotsium = Economics and society, 2018, no. 1 (44), pp. 1379-1388. (In Russian).

10. Khotkin A.V. IT used to optimize modern banks activity. Teoriya i praktika obshchestvennogo razvitiya = Theory and Practice of Social Development, 2018, no. 6, pp. 59-62. (In Russian).

11. Tabunschikov Yu.A. Digitalization of Economy - a Global Trend. Energosberezhenie = Energy Saving Technologies, 2018, no. 7, pp. 1-13. (In Russian).

12. Kazarenkova N.P., Svetovtseva T.A. Transformation of Russian Banking System under the Influence of Digital Economy. Izvestiya Yugo-Zapadnogo gosudarstvennogo universiteta. Seriya: Ekonomika. Sotsiologiya. Menedzhment = Proceedings of South-West State University. Series: Economy. Sociology. Management, 2018, vol. 8, no. 4 (29), pp. 188-195. (In Russian).

13. Westerman G., Bonnet D., McAfee A. Devyat' osnov tsifrovoi transformatsii [The Nine Elements of Digital Transformation]. Available at: http://tops.ru/blog/9_osnov_digital_transformacii. (In Russian).

\section{Информация об авторе}

Бубнова Юлия Борисовна - кандидат экономических наук, доцент, кафедра финансов и финансовых институтов, Байкальский государственный университет, г. Иркутск, Российская Федерация, e-mail: 23bal@mail.ru.

\section{Для цитирования}

Бубнова Ю.Б. Трансформация бизнес-модели банка в условиях цифровой экономики / Ю.Б. Бубнова / / Известия Байкальского государственного университета. - 2019. - Т. 29, № 3. - С. 425-433. DOI: $10.17150 / 2500-2759.2019 .29(3) .425-433$.

\section{Author}

Yulia B. Bubnova - Ph.D. in Economics, Associate Professor, Department of Finance and Financial Institutions, Baikal State University, Irkutsk, the Russian Federation, e-mail: 23bal@mail.ru.

\section{For Citation}

Bubnova Yu.B. Transformation of Bank's Business Model in Terms of Digital Economy. Izvestiya Baikal'skogo gosudarstvennogo universiteta $=$ Bulletin of Baikal State University, 2019, vol. 29, no. 3, pp. 425-433. DOI: 10.17150/2500-2759.2019.29(3).425-433. (In Russian). 